\title{
Sexual dysfunction in women in the reproductive age with rheumatoid arthritis: A case-control study
}

\author{
Hussein Ghanem ${ }^{1}$, Ahmed Ragab ${ }^{2}$, Nashaat Nabil', Shimaa Hamdy ${ }^{3}$, Islam F. S. \\ Abdelrahman ${ }^{1}$ \\ Original \\ Article \\ ${ }^{1}$ Department of Andrology, Faculty of Medicine, Cairo Universiy, Egypt \\ 2Department of Andrology, Faculty of Medicine, Beni-Suef University, Egypt \\ ${ }^{3}$ Department of Dermatology and Venereology, Fayoum General Hospital, Fayoum, \\ Egypt
}

\begin{abstract}
Introduction: Rheumatoid arthritis (RA) is a widespread disease that has a profound effect on the patient's quality of life. Aim:The aim was to evaluate the rate of sexual dysfunction (SD) in women with RA and to assess the possible association between SD and disease activity, severity of morning stiffness, functional disability and psychological status.

Patients and Methods: A case-control study was conducted on 200 sexually active, women in the reproductive age. A total of 100 women with RA attending the rheumatology clinics of two reference hospitals in Upper Egypt and 100 arthritis-free age- and sex-matched healthy controls were compared regarding the scores of Arabic Female Sexual Function Index (ArFSFI) and Hospital anxiety and depression scale (HADS). Additionally, women with RA were evaluated via Health Assessment Questionnaire (HAQ) and Disease Activity Score (DAS-28).

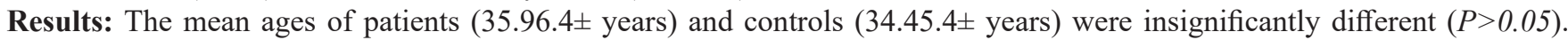
Mean FSFI total and domain scores of patients were significantly lower than controls $(P<0.001)$. Overall, $94 \%$ of patients and $30 \%$ of controls $(P<0.001)$ reported SD. Among women with RA (n: 100), lower SF scores were reported among those with morning stiffness (n: 14, $P<0.05$ ). Women with RA who exhibited SD had higher levels of anxiety, depression, and disease activity $(P<0.05)$ than those without SD. However, both subgroups were not different regarding HAQ.

Conclusion: The present study found an SD rate of $94 \%$ among sexually active women with RA. RA could have an extensively negative effect on all aspects of female sexuality, particularly on lubrication and orgasm dimensions. Moreover, SD in women with RA is significantly associated with disease activity, severity of morning stiffness, depression, and anxiety levels, but not with functional disability (HAQ).
\end{abstract}

Key Words: Depression, disease activity, female sexual function index, rheumatoid arthritis, sexual dysfunction

Received:20 April 2018, Accepted:08 May 2018

Corresponding Author: Islam F. S. Abdelrahman, MD, MRCS, FECSM, FEAA, Department of Andrology, Faculty of Medicine, Cairo University, Cairo, Egypt, Zip code: 11553, Fax: +20223687956, Tel.: +20 100424 4360, E-mail: islamandrology@yahoo.com

ISSN: 2090-6048, June 2018, Vol. 8, No. 2

\section{INTRODUCTION}

Rheumatoid arthritis (RA) is a systemic disease that has a profound effect on the patient's quality of life. Its characteristic feature is peripheral inflammatory synovitis ${ }^{[1]}$.

Sexual dysfunction (SD) is a common problem, affecting approximately $43 \%$ of women ${ }^{[2]}$; however, consequences of chronic diseases on sexuality are often underdiagnosed ${ }^{[3]}$. In RA, diminished sexual motivation, competence, and expression may result in difficult sexual functionality ${ }^{[1]}$.

Although $\mathrm{SD}$ is a significant problem in RA, there is inadequate information about this condition ${ }^{[4]}$. The aim of this work was to evaluate the rate of SD among women with RA attending the rheumatology clinics of two reference hospitals in Upper Egypt and to appraise the possible association between SD and disease activity, severity of morning stiffness, functional disability, and psychological status.

\section{MATERIALS AND METHODS}

Study design and setting:

This was an observational case-control study conducted in Andrology department, Beni-Suef University hospital (Beni-Suef, Egypt) in collaboration with Rheumatology units of Beni-Suef University and Fayoum General Hospital (Fayoum, Egypt) between September 2014 and 
November 2015. Each participant signed an informed consent before starting this study according to the regulations of the local Research Ethical Committee.

\section{Study participants:}

This study included 100 women with RA and 100 healthy women as a control group recruited from patients attending Rheumatology outpatient clinics and patients' family members or relatives, respectively. Participants were included only if they were in the reproductive age group, between 20 and 45 years, with regular menses; married; and sexually active during the past month. All women were asked directly if their husbands had sexual problems, that is, erectile dysfunction or premature ejaculation, and if the answer was yes, they were excluded from the study. All patients met the 1987 American College of Rheumatology criteria for $\mathrm{RA}^{[5]}$ and were without extra-articular manifestations. Exclusion criteria were altered mental status; smoking; drugs affecting SF (e.g. antidepressants); pregnant, breastfeeding, or postpartum females; gynecological problems (e.g. polycystic ovary syndrome); lower urinary tract symptoms; major pelvic surgery; concomitant chronic, endocrine, or major psychiatric disorders; and distressing male sexual problems.

\section{Instruments:}

The instruments used to collected data are as follows:

(1) A demographic and clinical data collection form.

(2) The Arabic version of Female Sexual Function Index (ArFSFI): The $\mathrm{ArFSFI}^{[6]}$, a 19-item scale grouped into six domains, was used to assess the SF of all participants during the past 4 weeks. Each item was scored on a scale of 0 or 1-5. Each domain score was calculated through summing up the scores of that domain's questions and multiplying the obtained number by a multiplier factor of that domain. Participants were categorized into either sexually functional or sexually dysfunctional considering the cutoff score of 26.55. The cutoff scores in a particular domain were as follows: less than 4.28 , less than 5.08, less than 5.45, less than 5.05, less than 5.04, and less than 5.51 in the desire, arousal, lubrication, orgasm, satisfaction, and pain domains, respectively ${ }^{[7]}$. FSFI total and domain scores were compared between the study groups.

(3) The Arabic version of Hospital anxiety and depression scale (HADS): The HADS included anxiety (HADS-A) and depression (HADS-D) subscales, and each subscale had seven items ${ }^{[8,9]}$. The Arabic version of HADS was used to assess the psychological well-being of the participants. Each item was rated from 0 to 3 . Values of greater than or equal to $11,8-10$, and less than or equal to 7 with either subscales indicated a definite case of psychiatric comorbidity, a borderline case, and a non-case of anxiety and depression, respectively. Each subscale score was compared between patients and controls and was correlated with the FSFI scores. Additionally, psychological status was evaluated between sexually functional and sexually dysfunctional RA subgroups.

(4) The Arabic version of Health Assessment Questionnaire Disability Index (HAQ-DI) : HAQ is a 20 -item scale grouped into eight subscales ${ }^{[10,11]}$. The Arabic version of HAQ was used to assess functional disability over the past week. The response categories were 'without any difficulty', 'with some difficulty', 'with much difficulty', and 'unable to do'. Additional questions included whether help from another person or devices was needed for each of the eight categories. Total score is between 0 and 3 , with 0 indicating no functional impairment and 3 indicating complete impairment.

HAQ scores of patients were estimated and correlated with their SF and psychological status. Moreover, disability was compared between sexually functional and sexually dysfunctional RA subgroups.

(5) Disease Activity Score 28 (DAS-28) : DAS-28 $8^{[12]}$ was used for evaluation of disease activity. This scoring considers the count of tender joints (TJC), swollen joints (SJC), ESR and Patients' Global Assessment (PGA) [pain level on a visual analogue scale (VAS)]. The final score was calculated by the following formula: DAS-28=

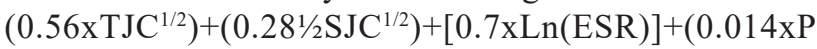
GA). Values of less than or equal to 3.2 , less than 2.6 , greater than 5.1, and greater than 3.2 to less than or equal to 5.1 were defined as the threshold for a low activity, remission, high activity, and moderate activity, respectively.

Differences in SF were evaluated among patients with various categories of disease activity. Besides, disease activity was checked among patients with RA with or without SD.

\section{Statistical analysis:}

Both groups were compared via $\chi 2$-test and t-test. Analysis of variance was used to evaluate the difference in multiple subgroups. The relation between numerical variables was tested using the Pearson correlation (r). The IBM SPSS version 20 (SPSS Inc., Chicago, Illinois, USA) was used for analysis. The significance was set at $P$ less than 0.05 .

\section{RESULTS}

Women with RA had a mean age of $35.9 \pm 6.4$ years and a mean disease duration of $2.17 \pm 1.1$ years. Controls had an average age of $34.4 \pm 5.4$ years. Both groups were comparable in terms of sociodemographic characteristics $(P>0.05)$. However, patients reported significantly 
higher HADS subscale scores compared with controls $(P<0.001)$. The mean scores of DAS and HAQ-DI among cases were $4.48 \pm 1.1$ and $1.92 \pm 0.61$, respectively. Moreover, 14, 56, and $30 \%$ of patients had remission, moderate, and severe categories of disease activity, respectively (Table 1).

Patients reported significantly $(P<0.001)$ lower sexual function (SF) total and domain scores compared with controls (Tables 1 and 2). Moreover, patients showed significantly $(P<0.001)$ higher frequency of abnormality related to FSFI total ( 94 vs. 30\%) and domain scores compared with controls (Table 3 ).

The FSFI total scores were insignificantly different $(P>0.05)$ among patients as rated by residence, occupational status, educational level, and age groups. However, significantly $(P<0.05)$ lower SF scores were reported among patients with morning stiffness $(14 / 100)$ (Table 4).

Higher percentages of patients $(P<0.001)$ reported abnormality on HADS subscales, whereas most controls reported normal levels of psychological well-being (Table 5).

There was a highly significant negative correlation $(P<0.001)$ between FSFI total scores and both HADS-A $(\mathrm{r}=-0.70)$ and HADS-D scores $(\mathrm{r}=-0.69)$ among patients. FSFI total scores were negatively correlated $(\mathrm{r}=-0.32$, $P=0.01)$ with DAS, but not correlated $(P>0.05)$ with patients' age, menarche age, age of marriage, number of pregnancies, BMI, and HAQ (Table 6).

There were significant differences $(P<0.05)$ between the mean total FSFI among three categories of disease activity. Analysis showed highly significant $(P<0.001)$ difference between the remission and the high disease activity groups (Table 7).

There were insignificant differences between patients with RA with and without SD regarding HAQ score $(P=0.4)$, whereas there were statistical differences between the two subgroups regarding HADS-A $(P=0.01)$, HADS-D $(P<0.001)$ and DAS $(P=0.03)$ (Table 8$)$.

Table 1: Demographic and clinical characteristics of the study groups

\begin{tabular}{|c|c|c|c|}
\hline Variables & Cases $(n=100)$ & Controls $(n=100)$ & $P^{\mathrm{a}}$ \\
\hline Age (years) & $35.9 \pm 6.4$ & $34.4 \pm 5.4$ & 0.07 \\
\hline \multicolumn{4}{|l|}{ Residence } \\
\hline Urban & $(42 \%)$ & $(48 \%)$ & 0.5 \\
\hline Rural & $(58 \%)$ & $(52 \%)$ & \\
\hline \multicolumn{4}{|l|}{ Occupational status } \\
\hline Employed & $(24 \%)$ & $(26 \%)$ & 0.9 \\
\hline Unemployed & $(76 \%)$ & $(74 \%)$ & \\
\hline \multicolumn{4}{|l|}{ Educational level } \\
\hline Secondary school & $(80 \%)$ & $(77 \%)$ & 0.7 \\
\hline University graduate & $(20 \%)$ & $(23 \%)$ & \\
\hline Age of partner (years) & $40.2 \pm 5.3$ & $39.4 \pm 4.9$ & 0.3 \\
\hline \multicolumn{4}{|l|}{ Menstrual status } \\
\hline Regular & $(82 \%)$ & $(87 \%)$ & 0.3 \\
\hline Irregular & $(18 \%)$ & $(13 \%)$ & \\
\hline
\end{tabular}




\begin{tabular}{lccc} 
Age of menarche (years) & $11.4 \pm 1.2$ & $11.4 \pm 1.1$ & W \\
Age of marriage (years) & $20.6 \pm 3.3$ & $20.2 \pm 1.9$ & 0.2 \\
Number of pregnancies & $3.4 \pm 1.7$ & $3 \pm 1.4$ & 0.3 \\
BMI $\left(\mathrm{kg} / \mathrm{m}^{2}\right)$ & $28.7 \pm 3.5$ & $28.2 \pm 4.6$ & $<0.001^{* * *}$ \\
FSFI overall scores & $18.8 \pm 5.7$ & $29.4 \pm 3$ & $<0.001^{* * *}$ \\
HADS scores & & \\
Anxiety subscale (HADS-A) & $12.5 \pm 2.3$ & $5.9 \pm 1.7$ & \\
Depression subscale (HADS-D) & $11.7 \pm 2$ & $6.2 \pm 1.4$ & \\
Disease activity & & \\
Remission & $(14 \%)$ & & \\
Moderate activity & $(56 \%)$ & \\
High activity & $(30 \%)$ & \\
Mean DAS-28 score & $4.48 \pm 1.1$ & \\
HAQ-DI score & $1.92 \pm 0.61$ & \\
\hline
\end{tabular}

Values are mean $\pm \mathrm{SD}$ or frequency $(\%)$--

DAS, Disease Activity Score; FSFI, Female Sexual Function Index; HADS, Health Anxiety and Depression Scale; HAQ-DI, Health Assessment Questionnaire Disability Index.

${ }^{a} \chi^{2}$-test was used for comparing qualitative variables and t-test for quantitative variables.

$* * *$ Highly significant.

Table 2 : FSFI domain scores of both groups

\begin{tabular}{llll}
\hline Variables & Cases $(\mathrm{n}=100)$ & Controls $(\mathrm{n}=100)$ & $P^{a}$ \\
\hline Desire & $2.8 \pm 0.93$ & $4.6 \pm 0.92$ & $<0.001^{* * *}$ \\
Arousal & $3 \pm 0.92$ & $4.7 \pm 0.92$ & $<0.001^{* * *}$ \\
Lubrication & $3.2 \pm 1$ & $5 \pm 0.38$ & $<0.001^{* * *}$ \\
Orgasm & $3.01 \pm 1.1$ & $5 \pm 0.53$ & $<0.001^{* * *}$ \\
Satisfaction & $3.1 \pm 1.3$ & $5.03 \pm 0.34$ & $<0.001^{* * *}$ \\
Pain & $3.7 \pm 1.1$ & $5.2 \pm 0.40$ & $<0.001^{* * *}$ \\
\hline
\end{tabular}

Values are represented as mean $\pm \mathrm{SD}$.

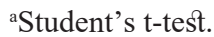

***Highly significant. 
Table 3: Frequency of women with abnormal Female Sexual Function Index (total and domain) scores in both groups

\begin{tabular}{|c|c|c|c|c|}
\hline Abnormal variables & Dysfunctional threshold & Cases $(n=100)$ & Controls $(n=100)$ & $P^{\mathrm{a}}$ \\
\hline Desire & 4.28 & $(91 \%)$ & $(39 \%)$ & $<0.001 * * *$ \\
\hline Arousal & 5.08 & $(98 \%)$ & $(58 \%)$ & $<0.001 * * *$ \\
\hline Lubrication & 5.45 & $(100 \%)$ & $(70 \%)$ & $<0.001 * * *$ \\
\hline Orgasm & 5.05 & $(100 \%)$ & $(51 \%)$ & $<0.001 * * *$ \\
\hline Satisfaction & 5.04 & $(99 \%)$ & $(64 \%)$ & $<0.001 * * *$ \\
\hline Pain & 5.51 & $(99 \%)$ & $(69 \%)$ & $<0.001 * * *$ \\
\hline Total score & 26.55 & $(94 \%)$ & $(30 \%)$ & $<0.001 * * *$ \\
\hline
\end{tabular}

Values are frequency $(\%)$.

${ }^{\mathrm{a}} \chi^{2-}$ test.

***Highly significant.

Table 4 : Sexual function regarding demographic characteristics, and morning stiffness in patients' group (n=100)

\begin{tabular}{|c|c|c|}
\hline Variables & FSFI total scores & $P^{\mathrm{a}}$ \\
\hline \multicolumn{3}{|l|}{ Residence } \\
\hline Urban $(n=42)$ & $24.01 \pm 6.8$ & 0.8 \\
\hline Rural (n=58) & $24.2 \pm 7.1$ & \\
\hline \multicolumn{3}{|l|}{ Occupational status } \\
\hline Employed $(n=24)$ & $23.1 \pm 7.7$ & 0.3 \\
\hline Unemployed $(\mathrm{n}=76)$ & $24.4 \pm 6.7$ & \\
\hline \multicolumn{3}{|l|}{ Educational level } \\
\hline Secondary school $(n=80)$ & $24.1 \pm 6.8$ & 0.9 \\
\hline University graduate $(\mathrm{n}=20)$ & $24.2 \pm 7.4$ & \\
\hline \multicolumn{3}{|l|}{ Age (years) } \\
\hline$\leq 30(\mathrm{n}=22)$ & $18.1 \pm 5.4$ & 0.9 \\
\hline $31-40(n=54)$ & $18.1 \pm 5.2$ & \\
\hline$\geq 41(\mathrm{n}=24)$ & $18.6 \pm 5.6$ & \\
\hline \multicolumn{3}{|l|}{ Morning stiffness (>1 h) } \\
\hline Cases with morning stiffness $(n=14)$ & $17.2 \pm 6.4$ & $0.01^{*}$ \\
\hline Cases without morning stiffness $(n=86)$ & $21.8 \pm 5.5$ & \\
\hline
\end{tabular}

Values are mean \pm SD.

aStudent's t-test was used for comparing two subgroups, analysis of variance for more than two subgroups.

* Statistically significant. 
Table 5: Frequency of women with possible or probable anxiety and depression in two groups

\begin{tabular}{|c|c|c|c|}
\hline HADS & Cases $(n=100)$ & Controls $(\mathrm{n}=100)$ & $P^{\mathrm{a}}$ \\
\hline \multicolumn{4}{|c|}{$\begin{array}{l}\text { Anxiety subscale (HADS-A) } \\
\text { score }\end{array}$} \\
\hline Normal $(\leq 7)$ & $(1 \%)$ & $(88 \%)$ & $<0.001 * * *$ \\
\hline Borderline case (8-10) & $(18 \%)$ & $(9 \%)$ & \\
\hline Definite case $(\geq 11)$ & $(81 \%)$ & $(3 \%)$ & \\
\hline \multicolumn{4}{|c|}{$\begin{array}{l}\text { Depression subscale (HADS-D) } \\
\text { score }\end{array}$} \\
\hline Normal $(\leq 7)$ & $(2 \%)$ & $(78 \%)$ & $<0.001 * * *$ \\
\hline Borderline case $(8-10)$ & $(28 \%)$ & $(20 \%)$ & \\
\hline Definite case $(\geq 11)$ & $(70 \%)$ & $(2 \%)$ & \\
\hline
\end{tabular}

Values are represented as frequency (\%).

HADS, Health Anxiety and Depression Scale; HAQ-DI, Health Assessment Questionnaire Disability Index.

${ }^{\mathrm{a}} \chi^{2-}$ test.

$* * *$ Highly significant.

Table 6: Correlation between Female Sexual Function Index total scores and clinico-demographic factors among patients ( $\mathrm{n}=100$ )

\begin{tabular}{|c|c|c|}
\hline & \multicolumn{2}{|c|}{ FSFI score } \\
\hline Variables & $\mathrm{r}$ & $P^{\mathrm{a}}$ \\
\hline HADS anxiety subscale score & -0.70 & $<0.0001 * * *$ \\
\hline HADS depression subscale score & -0.69 & $<0.0001 * * *$ \\
\hline DAS-28 score & -0.32 & $0.01 * *$ \\
\hline HAQ-DI score & 0.12 & 0.07 \\
\hline Age (years) & -0.08 & 0.3 \\
\hline Age of menarche (years) & 0.02 & 0.8 \\
\hline Age of marriage (years) & -0.14 & 0.055 \\
\hline Number of pregnancies & 0.007 & 0.9 \\
\hline BMI (kg/m2) & -0.0 .12 & 0.07 \\
\hline
\end{tabular}

DAS, Disease Activity Score; FSFI, Female Sexual Function Index; HADS, Health Anxiety and Depression Scale; HAQ-DI, Health Assessment Questionnaire Disability Index.

a'Bivariate Pearson's correlation.

**Statistically significant.

***Highly significant. 
Table 7: Mean Female Sexual Function Index score among patients with various categories of disease activity

\begin{tabular}{llll}
\hline & Remission $(\mathrm{n}=14)$ & Moderate activity $(\mathrm{n}=56)$ & High activity $(\mathrm{n}=30)$ \\
\hline FSFI score & $21.4 \pm 5$ & $19.2 \pm 5.4$ & $17.1 \pm 6.2$ \\
\hline
\end{tabular}

Values are represented as mean \pm SD.

FSFI, Female Sexual Function Index.

${ }^{a}$ Analysis of variance test and post-hoc comparisons.

*Statistically significant: remission versus moderate, $P=0.042$; remission versus high, $P=0.001$; moderate versus severe, $P=0.012$.

Table 8: Psychological status, disease activity and disability among patients with or without impaired SF

\begin{tabular}{|c|c|c|c|}
\hline Variables & RA with impaired SF $(n=94)$ & RA with normal SF $(n=6)$ & $P^{\mathrm{a}}$ \\
\hline HADS anxiety & $12.5 \pm 2.3$ & $9.3 \pm 3.1$ & $0.01 *$ \\
\hline HADS depression & $11.7 \pm 2$ & $7.1 \pm 1.9$ & $<0.001 * * *$ \\
\hline DAS28 & $4.5 \pm 1.1$ & $3.4 \pm 1.2$ & $0.03 *$ \\
\hline HAQ & $1.9 \pm 0.6$ & $2.1 \pm 0.4$ & 0.4 \\
\hline
\end{tabular}

DAS, Disease Activity Score; HADS, Health Anxiety and Depression Scale; HAQ-DI, Health Assessment Questionnaire Disability Index; RA, rheumatoid arthritis; SF, sexual function.

aStudent's t-test.

*Statistically significant.

***Highly significant.

\section{DISCUSSION}

This study attempted to evaluate the SF in a sample of Egyptian women. Previous studies have shown high prevalence of FSD in Egypt ${ }^{[13-16]}$.

Assessment of sexuality has been largely neglected in the care of patients with $\mathrm{RA}^{[1]}$. The study sample comprised 100 women with RA and 100 controls. Considering the conservative nature of the Egyptian women, the present sample was only reached after proper counselling and confirmed confidentiality. In many areas in the Arab world, including Egypt, culture prohibits openly discussing sexual matters ${ }^{[16]}$. A Malaysian study ${ }^{[17]}$ conducted to assess $\mathrm{SF}$ in women with RA mentioned various difficulties in convincing patients from two centers to participate.

In this study, we tried to strictly exclude cases with associated morbidities or drug treatment cases, except for antirheumatics, to preclude their possible effects on SF and to confirm that the detected SD was intensely related to RA or its therapy. A recent Taiwanese study ${ }^{[18]}$ had shown that FSD was more common in women with RA who had a comorbid chronic medical condition, as well as those with further depressive symptoms.

Patients and controls were homogenous regarding sociodemographic characteristics, which indicates proper selection and matching of the participants. Moreover, sexually active patients and controls had average ages of $35.9 \pm 6.4$ years and $34.4 \pm 5.4$ years, respectively, which were comparable to those reported in an Iranian study assessing FSD in patients with $\mathrm{RA}^{[19]}$. Conversely, studies assessing FSD in western women with RA revealed a significantly higher mean ages among sexually active participants $^{[1,20]}$.

The present study found an FSD rate of 94\% among patients, which was consistent with the rate of $93.7 \%$ reported by Aras et al. ${ }^{[1]}$. This rate was considerably greater compared with the figures published by Egyptian $^{[21,22]}$ and non-Egyptian ${ }^{[18,23-25]}$ authors assessing SF among women with RA. Using the short version of the Questionnaire for Screening of SD among women with RA reported a sexual difficulty rate of $51 \%{ }^{20]}$.

The FSD rate of $30 \%$ detected in controls was significantly lower than that reported by Aras et al. ${ }^{[1]}$ and 
Hari et al. ${ }^{[24]}$, but significantly higher than the rate of $15 \%$ mentioned by Coskun et al. ${ }^{[23]}$.

Women with RA reported lower total FSFI scores compared with controls. Similar findings were reported by prior authors ${ }^{[1,20,23,24,26]}$. However, the SF scores of the studied control group $(29.4 \pm 3)$ were significantly higher than those reported for controls by Aras et al. ${ }^{[1]}$ and Hari et al. ${ }^{[24]}$, and slightly higher than scores of $27.29 \pm 5.68$ reported by Maasoumi et al. ${ }^{[19]}$. In contrast, other studies ${ }^{[23,26]}$ reported higher mean total FSFI scores among controls.

This study demonstrated lower FSFI domain scores in patients than in controls. Similar findings were reported by previous authors ${ }^{[1,19,26]}$. Others ${ }^{[23,24]}$ found that all sexuality dimensions were affected in women with RA except pain. One study showed that satisfaction and pain among women with RA were not statistically different compared with controls $^{[20]}$.

Lubrication and orgasm domains were impaired in all patients, whereas desire was the least affected dimension (91\%). El Miedany et al. ${ }^{[22]}$ found that pain was the least contributing domain in patients with RA with SD $(73 \%)$, whereas orgasmic disorder was the most prevalent $(96.8 \%)$. Shahar et al. ${ }^{[27]}$ revealed that satisfaction domain was the most affected among patients with RA (49\%), and orgasm was the least affected domain (7.8\%). Besides, Lin et al. ${ }^{[18]}$ revealed highest standardized score (mean/total score ' $\%$ ') with satisfaction domain, whereas arousal showed the lowest standardized score.

The present study revealed that $70 \%$ and $81 \%$ of patients reported definite depression and anxiety, respectively. Yilmaz et al. ${ }^{[26]}$ found a depression rate of $47.4 \%$ among women with RA using Beck Depression Inventory (BDI).

Statistical analysis revealed that patients had significantly higher scores of both HADS subscales than controls. Besides, Aras et al. ${ }^{[1]}$ found non-significant difference between patients and controls regarding HADS subscales; however, they found a significant difference within RA group between patients with or without SD concerning only depression. Yilmaz et al. $^{[26]}$ and Coskun et $a l .{ }^{[23]}$ found that BDI scores for patients with RA were greater than control group.

Yilmaz et al. ${ }^{[26]}$ found a moderate negative correlation between SF and BDI. In this study, psychological status was significantly related to SD. This finding was consistent with previous studies ${ }^{[1,18,22,28-30]}$.

The present study revealed non-significant relationship between SD and HAQ. This was in line with previous studies $^{[1,24,27,31]}$. However, contrary observations were found by other authors ${ }^{[21,26]}$. Akkus et al. ${ }^{[32]}$ and van Berlo et $a .^{[20]}$ reported that poor physical functioning was associated with low sexual satisfaction.

The mean DAS-28 score of $4.48 \pm 1.1$ reported in the patients was somewhat higher than scores of $3.6 \pm 1.5$ and $3.65 \pm 1.2$ reported by Costa et al. ${ }^{[31]}$ and Yilmaz et al. ${ }^{[26]}$, respectively. Moreover, $56 \%$ of cases had moderate disease activity, in whom the SF total scores were different from groups with remission and high disease activity. Shahar et al. $^{[27]}$ found moderate activity among 54.8\% of patients and only $11.3 \%$ were in remission. Yilmaz et $a l^{[26]}$ found moderate activity in less than $50 \%$ of patients. They noted that FSFI total scores of the group in remission and with mild disease activity were different from those with moderate and high disease activity.

Herein, DAS-28 was inversely proportional to SF total scores. These findings were comparable to other studies ${ }^{[18,22,26]}$. Likewise, Akkus et al. ${ }^{[32]}$ reported that satisfaction scores were negatively correlated with DAS. Contrary observations were found by other authors ${ }^{[1,32]}$. Shahar et al. ${ }^{[27]}$ found significant correlations between DAS and low desire and arousal, but not with total FSFI scores.

The present study revealed that SF in patients with morning stiffness were significantly lower than those without morning stiffness. Similar results were reported by Yilmaz et al. ${ }^{[26]}$. Coskun et al. ${ }^{[23]}$ found significant results regarding only satisfaction and total domain scores. Likewise, Gutweniger et al. ${ }^{[33]}$ reported that sexual dissatisfaction is increased in parallel with increased morning stiffness.

There were significant differences between patients with RA with or without SD concerning HADS subscales and DAS, but not concerning HAQ. Aras et al. ${ }^{[1]}$ found significant results only regarding depression. Shahar et $a .^{[27]}$ and Costa et al. ${ }^{[31]}$ found nonsignificant results concerning HAQ and DAS.

Statistical analysis showed that SF was not correlated with patients' age, or age of marriage. Similarly, Hari et al. ${ }^{[24]}$ found no correlation between age and SF. Other authors $^{[2,18,26,31]}$ reported an inevitable effect of aging on SF. Shahar et al. ${ }^{[27]}$ revealed significant correlations between SF and patient's age besides duration of marriage. However, Maasoumi et al. ${ }^{[19]}$ found non-significant correlation between SF and duration of marriage.

The present study revealed that educational level had no significant effect on FSD. These findings were consistent with other studies ${ }^{[31,34,35]}$. In contrast, some authors found that FSD was inversely ${ }^{[18,36-38]}$ or directly ${ }^{[14,18]}$ related to educational level. 
Studies on patients with RA suggested that obesity was associated with a worse quality of life and with a more active disease ${ }^{[39,40]}$. Yilmaz et al. ${ }^{[26]}$ revealed weak correlations between SF and BMI. However, this study revealed no correlation between SF and BMI.

The small number of the participants in the groups is a limiting factor in this study because of the conservative nature of the Egyptian community. Additionally, male partner sexual status was not evaluated using the International Index of Erectile Function scale. Erectile functions of the partners were asked, and the women whose partner had suspicious erectile dysfunction were not included in the study.

\section{CONCLUSION}

The present study found a SD rate of $94 \%$ among sexually active women with RA. RA could have an extensively negative effect on all aspects of female sexuality, particularly on lubrication and orgasm dimensions. SD is significantly associated with disease activity, severity of morning stiffness, depression, and anxiety levels but not with functional disability (HAQ score). Further longitudinal multicenter studies are necessary to clarify the causal association and the mechanism of correlation between RA and FSD. Finally, sexual and psychological care should be wisely presented by health professionals during the management of patients with RA.

\section{CONFLICT OF INTEREST}

There are no conflict of interests.

\section{REFERENCES}

1. Aras H, Aras B, Icagasioglu A, Yumusakhuylu, Kemahli E, Haliloglu S. et al. Sexual dysfunction in women with rheumatoid arthritis. Med Glas (Zenica) 2013; 10:327-331.

2. Laumann EO, Paik A, Rosen RC. Sexual dysfunction in the United States: prevalence and predictors. JAMA 1999; 281:537-544.

3. Josefsson KA, Gard G. Sexual health in patients with rheumatoid arthritis: experiences, needs and communication with health care professionals. Musculoskeletal Care 2012; 10:76-89.

4. Ferreira Cde C, da Mota LM, Oliveira AC, de Carvalho JF, Lima RA, Simaan CK, et al. Frequency of sexual dysfunction in women with rheumatic diseases. Rev Bras Reumatol 2013; 53:35-46.

5. Arnett FC, Edworthy SM, Bloch DA, McShane DJ, Fries JF, Cooper NS et al., The American
Rheumatism Association 1987 revised criteria for the classification of rheumatoid arthritis. Arthritis Rheum $1988 ; 31: 315-324$

6. Anis TH, Gheit SA, Saied HS, Al kherbash SA. Arabic translation of Female Sexual Function Index and validation in an Egyptian population. J Sex Med 2011; 8:3370-3378.

7. Wiegel M, Meston C, Rosen R. The female sexual function index (FSFI): cross-validation and development of clinical cutoff scores. J Sex Marital Ther 2005; 31:1-20.

8. El-Rufaie OE, Albar AA, Al-Dabal BK. Identifying anxiety and depressive disorders among primary care patients: a pilot study. Acta Psychiatr Scand 1988; 77:280-282.

9. Zigmond AS, Snaith RP. The hospital anxiety and depression scale. Acta Psychiatr Scand $1983 ; 67: 361-370$

10. Bruce B, Fries JF. The Stanford Health Assessment Questionnaire: dimensions and practical applications. Health Qual Life Outcomes 2003; 1:20.

11. El Meidany YM, El Gaafary MM, Ahmed I. Crosscultural adaptation and validation of an Arabic Health Assessment Questionnaire for use in rheumatoid arthritis patients. Joint Bone Spine 2003; 70:195-202.

12. Prevoo ML, van 't Hof MA, Kuper HH, van Leeuwen MA, van de Putte LB, van Riel PL. Modified disease activity scores that include twenty-eight-joint counts. Development and validation in a prospective longitudinal study of patients with rheumatoid arthritis. Arthritis Rheum 1995; 38:44-48.

13. Anis TH, Aboul Gheit S, Awad HH, Saied HS. Effects of female genital cutting on the sexual function of Egyptian women. A cross-sectional study. J Sex Med 2012; 9:2682-2692.

14. Elnashar AM, El-Dien Ibrahim M, El-Desoky MM, Ali OM, El-Sayd Mohamed Hassan M. Female sexual dysfunction in Lower Egypt. BJOG 2007; 114:201-206.

15. Hassanin IM, Helmy YA, Fathalla MM, Shahin AY Prevalence and characteristics of female sexual dysfunction in a sample of women from Upper Egypt. Int J Gynaecol Obstet 2010; 108:219-223.

16. Ibrahim ZM, Ahmed MR, Sayed Ahmed WA. Prevalence and risk factors for female sexual 
dysfunction among Egyptian women. Arch Gynecol Obstet 2013; 287:1173-1180.

17. Sidi H, Abdullah N, Puteh SE, Midin M. The Female Sexual Function Index (FSFI): validation of the Malay version. J Sex Med 2007; 4:1642-1654.

18. Lin MC, Lu MC, Livneh H, Lai NS, Guo HR, Tsai TY. Factors associated with sexual dysfunction in Taiwanese females with rheumatoid arthritis. BMC Womens Health 2017; 17:12.

19. Maasoumi R, Moridi M, Farhadi F, Moshfeghi Z. Sexual function in women with rheumatoid arthritis. Women's Health Bull 2014; 10:327-331.

20. van Berlo WT, van de Wiel HB, Taal E, Rasker JJ, Weijmar Schultz WC, van Rijswijk MH. Sexual functioning of people with rheumatoid arthritis: a multicenter study. Clin Rheumatol 2007; 26:30-38.

21. Abdel-Nasser AM, Ali EI. Determinants of sexual disability and dissatisfaction in female patients with rheumatoid arthritis. Clin Rheumatol 2006; 25:822-830.

22. El Miedany Y, El Gaafary M, El Aroussy N, Youssef $\mathrm{S}$, Ahmed I. Sexual dysfunction in rheumatoid arthritis patients: arthritis and beyond. Clin Rheumatol 2012; 31:601-606.

23. Coskun B, Coskun BN, Atis G, Ergenekon E, Dilek $\mathrm{K}$. Evaluation of sexual function in women with rheumatoid arthritis. Urol J 2014; 10:1081-1087.

24. Hari A, Rostom S, Lahlou R, Bahiri R, HajjajHassouni N. Sexual function in Moroccan women with rheumatoid arthritis and its relationship with disease activity. Clin Rheumatol 2015; 34:1047-1051.

25. Tristano AG. The impact of rheumatic diseases on sexual function. Rheumatol Int 2009; 29:853-860.

26. Yilmaz H, Polat H A, Yilmaz SD, Erkin G, Kucuksen $\mathrm{S}$, Sali A. et al., Evaluation of sexual dysfunction in women with rheumatoid arthritis: a controlled study. J Sex Med. 2012; 9:2664-2670.

27. Shahar MA, Hussein H, Sidi H, Shah SA, Mohamed Said MS. Sexual dysfunction and its determinants in Malaysian women with rheumatoid arthritis. Int J Rheum Dis 2012; 15:468-477.

28. Blake DJ, Maisiak R, Koplan A, Alarcon GS, Brown S. Sexual dysfunction among patients with arthritis. Clin Rheumatol 1988; 7:50-60.
29. Ehrlich GE. Social, economic, psychologic, and sexual outcomes in rheumatoid arthritis. Am J Med 1983; 75:27-34.

30. Kraaimaat FW, Bakker AH, Janssen E, Bijlsma JW. Intrusiveness of rheumatoid arthritis on sexuality in male and female patients living with a spouse. Arthritis Care Res 1996; 9:120-125.

31. Costa TF, Silva CR, Muniz LF, Mota LM. Prevalence of sexual dysfunction among female patients followed in a Brasilia Cohort of early rheumatoid arthritis. Rev Bras Reumatol 2015; 55:123-132.

32. Akkus Y, Nakas D, Kalyoncu U. Factors Affecting the Sexual Satisfaction of Patients with Rheumatoid Arthritis and Ankylosing Spondylitis. Sex Disabil 2010; 28:223-232.

33. Gutweniger S, Kopp M, Mur E, Gunther V. Body image of women with rheumatoid arthritis. Clin Exp Rheumatol 1999; 17:413-417.

34. Doruk H, Akbay E, Cayan S, Bozlu M, Acar D. Effect of diabetes mellitus on female sexual function and risk factors. Arch Androl 2005; 51:1-6.

35. Fatemi SS, Taghavi SM. Evaluation of sexual function in women with type 2 diabetes mellitus. Diab Vasc Dis Res 2009; 6:38-39.

36. Alizadeh NS, Arasteh M, Mohsenpour B, Karimian F. Comparison of sexual dysfunction between diabetic and non-diabetic women. J Midlife Health 2013; 4:167-171.

37. Owiredu WK, Amidu N, Alidu H, Sarpong C, GyasiSarpong CK. Determinants of sexual dysfunction among clinically diagnosed diabetic patients. Reprod Biol Endocrinol 2011; 9:70.

38. Singh JC, Tharyan P, Kekre NS, Singh G, Gopalakrishnan G. Prevalence and risk factors for female sexual dysfunction in women attending a medical clinic in south India. $J$ Postgrad Med 2009; 55:113-120.

39. Gracia-Poma A, Segami MI, Mora CS, Ugart MF, Terrazas HN Rho EA, et al. Obesity is independently associated with impaired quality of life in patients with rheumatoid arthritis. Clin Rheumatol 2007; 26:1831-1835.

40. Stavropoulos-Kalinoglou A, Metsios GS, Koutedakis Y, Kitas GD. Obesity in rheumatoid arthritis. Rheumatology (Oxford) 2011; 50:450-462. 